\title{
Emergence of Universal Grammar in foreign word adaptations*
}

Shigeko Shinohara, UPRESA 7018 University of Paris III/CNRS

\section{Introduction}

There has been a renewal of interest in the study of loanword phonology since the recent development of constraint-based theories. Such theories readily express target structures and modifications that foreign inputs are subject to (e.g. Paradis and Lebel 1994, Itô and Mester 1995a,b). Depending on how the foreign sounds are modified, we may be able to make inferences about aspects of the speaker's grammar for which the study of the native vocabulary is either inconclusive or uninformative. At the very least we expect foreign words to be modified in accordance with productive phonological processes and constraints (Silverman 1992, Paradis and Lebel 1994). It therefore comes as some surprise when patterns of systematic modification arise for which the rules and constraints of the native system have nothing to say or even worse contradict. I report a number of such "emergent" patterns that appear in our study of the adaptations of French words by speakers of Japanese (Shinohara 1997a,b, 2000). I claim that they pose a learnability problem. My working hypothesis is that these emergent patterns are reflections of Universal Grammar (UG). This is suggested by the fact that the emergent patterns typically correspond to well-established crosslinguistic markedness preferences that are overtly and robustly attested in the synchronic phonologies of numerous other languages. It is therefore natural to suppose that these emergent patterns follow from the default parameter settings or constraint rankings inherited from the initial stages of language acquisition that remain latent in the mature grammar. Thus, the study of foreign word adaptations can not only probe the final-state grammar but may also shed light on the initial state. The implication for L2 acquisition is that UG latent in L1 is accessible in a later stage in life (cf. Epstein, Flynn and Martohardjono 1996, see Broselow and Park (1995); Broselow, Chen and Wang (1998) reporting similar UG emergent patterns in their studies of inter-language phenomena). Of course this hypothesis awaits confirmation from acquisition studies.

Under the assumption made above about the emergence of the unmarked in foreign word adaptation, it is possible to derive evidence bearing on the default UG pattern(s) through the study of adapted forms. We will discuss default patterns as we analyse the data in the Optimality framework. In Optimality Theory (Prince and Smolensky 1993) (OT), the learning process of a particular language consists in determining the ranking of the universal constraints. In recent proposals on learning theory in OT (Smolensky (1996), Gnanadesikan (this volume), Davidson, Jusczyk and Smolensky (this volume), Prince and Tesar (this volume), Hayes (this volume)), the ranking of Markedness (M) over Faithfulness 
(F) constraints (or an equivalent in the learning process, see Hayes (this volume)) is presumed to be the default, initial state of the language faculty because such ranking leads to a more restrictive grammar. In the course of acquisition, the child will rerank $\mathrm{F}$ over $\mathrm{M}$ when provided with positive evidence of violation of markedness constraints. In this study we will examine several emergent patterns in adaptation data and characterise the constraint rankings they imply in terms of possible ranking schema: $\mathrm{M} \gg \mathrm{F}, \mathrm{M} \gg \mathrm{M}, \mathrm{F}>\mathrm{F}$ and $\mathrm{F} \gg \mathrm{M}$.

In the next section, I will provide more explanation about the data and adaptation process in Japanese. In section 3 I will explain the theoretical framework. Then, in the following sections, I will present examples of the "emergence of UG" patterns. The analyses of the data consist of three parts: in section 4 we will study the segmental level of adaptation, particularly assibilation of alveolar plosives; sections 5 and 6 treat pitch accent assignment and an aspect of syllabification, respectively. The paper closes with a summary and issues for future study.

\section{Data and adaptation process}

In this section, I will give some information about the data and sketch the general process of adaptation.

My study is based mainly on Japanese adaptations of French words (Shinohara 1997b) (English words are used for comparison in the study of accentuation). By "adaptation" I mean the process whereby native speakers of L1 adjust foreign words (L2) in such a way that the resulting forms are acceptable as L1 sound sequences. The following are Japanese adaptations of French and English (British "Received Pronunciation") words:

(1)

French word $\quad$ université |ynivERsite| /junibe'rusite ${ }^{1}$

English word university |jUnlvè:sIt | /juniba'asitii/

Data were collected from three speakers of Tokyo Japanese of the same generation (30-40 years old) residing in Paris. The informants are proficient in L2. They spent several years in the L2 environment (Northern Standard French) after high school education in Japan. They were asked to convert the sounds of French words in a written word list to Japanese ones employing the type of adaptation used in code-switching or by interpreters when a Japanese equivalent is not available (e.g. in the case of proper nouns). They produced the adapted forms for the author and the author transcribed them. The procedure was repeated after a few weeks so that any variation could be observed. I employed this method rather than collecting loanwords from a dictionary. Loanwords often reflect 
peculiarities of spelling as well as features of the dialect of the particular adapter that are difficult to control. Therefore, we will mainly study the adaptation process actively employed by our informants; however, loanwords will also be considered when they are comparable to the adapted forms.

The general process of adaptation is shown in (2). I suppose that the foreign input forms consist of phonemic strings of L2 (with certain prosodic features), rather than uncategorised sound sequences. The reason for this hypothesis is that there is a correspondence between the phonemes of L2 and L1, but not between their allophones. A phonemic categorisation of L2 sounds by L2 learners can be defective compared to that of L2 native speakers. For example, French phonemes $|\mathrm{e}|$ and $|\mathrm{E}|$ can be grouped as a single /e/ sound in the French sound system of Japanese or Spanish learners who have not yet acquired the distinction. Even if defective, without such an initial sound categorisation by L2 learners, it would be difficult to explain a systematic correspondence between the phonemes of L1 and L2. Concerning my informants, they are learners who have reached a good level of perception and production in L2. In the data obtained from my informants, the correspondence between phonemes is consistent (for a fuller discussion of input forms, see Shinohara (1997b) and Paradis and LaCharité (1997), and for an opposing view, see Silverman (1992)).

I recognise three levels in the process of Japanese adaptation, but they do not have to be ordered procedurally.

(2)

Process of adaptation

\begin{tabular}{|c|c|c|}
\hline Inputs: & French forms & Ex: $\frac{\text { calmer, }}{\mid \text { kalme }|,| \text { bac }}$ \\
\hline Segmental level & Segmental correspondence & karme, bak \\
\hline Syllabic level & $\begin{array}{l}\text { Vowel epenthesis, } \\
\text { Prefinal syllable lengthening }\end{array}$ & $\begin{array}{l}\text { karume, } \\
\text { bakku }\end{array}$ \\
\hline Accentual level & Pitch accent assignment & ka'rume, ba'kku \\
\hline Outputs: & Adapted forms & /ka'rume/, /ba'kku/ \\
\hline
\end{tabular}

On the segmental level, Japanese segments are substituted for French ones. Japanese syllable structure is relatively restricted; (3) below provides a list of the licit syllable types. When the input loanword contains a consonantal sequence that cannot be parsed into one of these syllable types, vowel epenthesis applies to allow the consonants to be syllabified. 
(3)

$\underline{\text { Syllable structure of Japanese }}$

Light syllable: $\quad(\mathrm{C})(\mathrm{j}) \mathrm{V} \quad$ (ex. /ha/ 'tooth', /tja/ 'tea')

Heavy syllables: $\quad$ (C)(j) VV (ex./too/ 'tower', /dai/ 'title)

(C)(j) $\mathrm{VN} \quad$ (ex. /teN/ [teN 'point')

(C)(j)VQ (ex. /haQ.pa/ [hap:a] 'leaf')

(N: moraic nasal)

(Q: moraic obstruent; the first half of a geminate obstruent)

On the syllabic level, the phenomenon I will call "pre-final lengthening" is also observed. When a foreign word ends in a syllable closed by a single consonant as in $|\mathrm{bak}| \mathrm{bac}$, the prefinal syllable of the adapted form is lengthened by a gemination as in /bakku/. On the accentual level, pitch accent is assigned. I will present some of the adaptation phenomena that appeared in each level in later sections.

\section{Constraint interaction}

In this section, I will explain briefly the theoretical framework that I will use and its significant consequences. The data are analysed in the Optimality framework (Prince and Smolensky 1993, McCarthy and Prince 1995). OT defines the grammar of a language as a hierarchy of universal constraints. The constraints are divided into two broad categories: Structural (or Markedness) constraints reflecting unmarked forms as defined by UG; Faithfulness constraints for preservation of input properties.

I will illustrate the interaction between the two types of constraints by taking the example of plosive assibilation. Assibilation is a process whereby a plosive becomes an affricate in certain phonological environments (cf. Walter 1988). For example, $[\mathrm{t}$ ] alternates with [ts] before high front vowels in Quebec French. The feature change in these segments is expressed by using aperture features (Steriade 1993):

(4)

Closure $\left[\mathrm{A}_{0}\right]$ : total absence of oral air flow.

Fricative $\left[\mathrm{A}_{\mathrm{f}}\right]$ : degree of oral aperture sufficient to produce a turbulent air stream.

Approximant $\left[\mathrm{A}_{\max }\right]$ : degree of oral aperture insufficient to produce a turbulent airflow.

According to Steriade (1993), a released plosive has a complex feature structure, $\left[\mathrm{A}_{0} \mathrm{~A}_{\mathrm{max}}\right]$. The first part $\left[\mathrm{A}_{0}\right]$ corresponds to the closure stage and the second part 
$\left[\mathrm{A}_{\max }\right]$ to the release stage. An affricate has the closure in common with a plosive, but the release is with friction, hence, its feature specification is $\left[\mathrm{A}_{0} \mathrm{~A}_{\mathrm{f}}\right]$.

Turning to Japanese, let us formulate two constraints in conflict regarding the assibilation of alveolar plosives :

(5)

Assibilation (*TU) : No coronal plosive is followed by a high non back vowel ${ }^{2}$.

Ident- $\left[\mathbf{A}_{\max }\right]$ : the release feature $\left[\mathrm{A}_{\max }\right]$ of a plosive must be identical in the input and the output.

Assibilation above is a Markedness constraint. Ident- $\left[\mathrm{A}_{\max }\right]$ belongs to the Faithfulness constraint family. In Tableau 1, the input /mat-u/ 'wait, non past' from a Japanese /t/-ending verb stem followed by the suffix /- $u /$ contains a /tu/ sequence. Suppose that this input $/ \mathrm{t} /$ has the plosive release feature $\left[\mathrm{A}_{\max }\right]$. When the markedness constraint dominates Faithfulness, the grammar neutralises the release feature of $/ \mathrm{t}$, and gives the output [matsu], with assibilation :

Tableau 1

Markedness $>>$ Faithfulness

\begin{tabular}{|c|l|l|}
\hline mat-u & $*$ TU & Ident- $\left[\mathrm{A}_{\max }\right]$ \\
\hline matu & $* !$ & \\
\hline$\rightarrow$ matsu & & $*$ \\
\hline
\end{tabular}

If the constraints are ranked in the reversed order Ident- $\left[\mathrm{A}_{\max }\right] \gg * \mathrm{TU}$, the consonant [t] will preserve its release feature, and the output is without assibilation, [matu] as shown below.

Tableau 2

Faithfulness $>>$ Markedness

\begin{tabular}{|c|l|l|}
\hline mat-u & Ident- $\left[\mathrm{A}_{\max }\right]$ & $*$ TU \\
\hline$\rightarrow$ matu & & $*$ \\
\hline matsu & $* !$ & \\
\hline
\end{tabular}

Assibilation is regularly present in Japanese native Yamato and Sino-Japanese lexicon, while recent borrowings violate this constraint. The loanword /tii/ $<$ tea is realised as [ti:] without assibilation. In my adaptation data, assibilation is also violated. For this discrepancy across strata I adopt the idea that the different behaviour of loanwords reflects a distinct grammar, where a minimal reranking from the native one has taken place (cf. Itô and Mester 1995b; for other approaches to sub-lexica, see Inkelas (1994), Fukazawa (1997)). Minimal reranking across strata in Itô and Mester's approach is to a large extent 
comparable to the acquisition process: once $\mathrm{F}$ ranks over $\mathrm{M}$ within a stratum with a positive evidence, in the next (newer) stratum this ranking remains as an established one instead of being reset to the initial state $M \gg F$ (relevant discussion is found in section 6.2.2).

With these analytic preliminaries completed, we now turn to some of the emergent patterns found in our study of Japanese adaptations.

\section{Emergent Pattern 1: Subdivision of the constraint *Affricate}

The first example of the emergence of UG in my data concerns the relative ranking of two markedness constraints on affricates. We will compare the assibilation of the alveolar plosives in two lexical strata, the native stratum and the stratum of relatively old loanwords. A difference in the treatment of voiced and voiceless alveolar plosives followed by a high vowel is observed in these strata. I will discuss three phenomena that are, in one way or another, influenced by the constraint of assibilation.

Let us first describe the facts in the native lexicon. In the native lexicon of Japanese, as we have seen in the preceding section, the alveolar plosives /t/ and /d/ surface as affricates before the high vowels /i/ and / $\mathrm{u} /$. As shown in examples a), b), c) in (6), input sequences /tu/ and /du/ give [tsu] and [dzu] in the output, respectively. In addition to the assibilation, for the voiced alveolar plosive, there is another phenomenon taking place. The input sequences /du/ (and /di/) neutralise with /zu/ (and /zi/). Examples c), f), i) show the case of affrication of the input sequences $/ \mathrm{du} /$ and /zu/ in post-nasal and word initial position, while d) and g) provide examples of frication in intervocalic position. Thus, we see that the closure feature $\left[\mathrm{A}_{\mathrm{f}}\right]$ (friction) of the input consonant $/ \mathrm{z} /$ and the $\left[\mathrm{A}_{0}\right]$ (occlusion) of the /d/ change on the surface depending on the environment. I will call this phenomenon "mutation". Mutation is a cover-term for the weakning/hardening process affecting voiced obstruents. The important point here is that mutation occurs only with the voiced alveolar plosive; the voiceless plosive does not mutate (cf. a), b), e), h)).

(6)

Assibilation and mutation in the native lexicon

a) /tuki/ [tsuki] 'moon'

b) /natu/ [natsu] 'summer'

c) /kaNduki/ [kandzuki] 'cold month'

d) /mikaduki/ [mikazuki] 'increasing moon'

e) $/ \mathrm{su} /[\mathrm{su}]$ 'vinegar'

f) $/ \mathrm{poNzu} /[\mathrm{pondzu}]$ 'vinegar with lemon' 
g) /gomazu/ [gomazu] 'vinegar with sesames'

h) $/$ nasu/ [nasu] 'aubergine'

i) /zubora/ [dzubora] 'laziness'

Let us first turn to analysis of assibilation and mutation in the native lexicon. I assume the universal constraint *Affricate, reflecting the markedness of affricates as opposed to plosives. To explain the fact that the mutation is observed for /d/ but not for /t/, I will split *Affricate into two sub-categories :

(7)

*DZ : Do not have voiced affricates.

*TS : Do not have voiceless affricates.

By using these two constraints, the mutation for /d/ and the absence of the mutation for $/ t /$ is explained as follows. On the one hand the Faithfulness constraint for the closure feature, Ident- $\left[\mathrm{A}_{0}\right]$ (see (8)) dominates $* \mathrm{TS}$, as illustrated in Tableau 3 below.

(8)

Ident- $\left[\mathbf{A}_{0}\right]$ : the feature $\left[\mathrm{A}_{0}\right]$ of corresponding segments in the input and in the output must be identical.

Tableau 3

I...tul

\begin{tabular}{|l|l|l|l|l|}
\hline & $\ldots \mathrm{tu}$ & $* \mathrm{TU}$ & Ident- $\left[\mathrm{A}_{0}\right]$ & $* \mathrm{TS}$ \\
\hline 1. & $\ldots \mathrm{tu}$ & $* !$ & & \\
\hline 2. & $\ldots \mathrm{su}$ & & $* !$ & \\
\hline $3 . \rightarrow$ & $\ldots \mathrm{tsu}$ & & & $*$ \\
\hline
\end{tabular}

On the other hand Ident- $\left[\mathrm{A}_{0}\right]$ is dominated by *DZ. Consequently, *DZ prevents the closure feature $\left(\mathrm{A}_{0}\right)$ of the voiced affricates from appearing in the output as shown in Tableau 4.

Tableau 4

/...du/

\begin{tabular}{|l|l|l|l|l|l|}
\hline & $\ldots \mathrm{du}$ & $* \mathrm{TU}$ & $* \mathrm{DZ}$ & Ident- $\left[\mathrm{A}_{0}\right]$ & $* \mathrm{TS}$ \\
\hline 1. & $\ldots \mathrm{du}$ & $* !$ & & & \\
\hline $2 . \rightarrow$ & $\ldots \mathrm{zu}$ & & & $*$ & \\
\hline 3. & $\ldots \mathrm{dzu}$ & & $* !$ & & \\
\hline
\end{tabular}


Finally, the distribution of $[\mathrm{dz}]$ in non intervocalic positions is accounted for by an undominated constraint $* \# Z$ (see (9)). Tableau 5 illustrate the effect of this ranking.

(9)

*\#Z : no voiced fricative in non intervocalic positions (i.e. the beginning of an utterance and postnasal position).

Tableau 5

/\#du/

\begin{tabular}{|l|l|l|l|l|l|l|}
\hline & $\# \mathrm{du}$ & $* \# \mathrm{Z}$ & $* \mathrm{TU}$ & $* \mathrm{DZ}$ & $\mathrm{Ident}-\left[\mathrm{A}_{0}\right]$ & $* \mathrm{TS}$ \\
\hline 1. & $\mathrm{du}$ & & $* !$ & & & \\
\hline 2. & $\mathrm{zu}$ & $* !$ & & & $*$ & \\
\hline $3 . \quad \rightarrow$ & $\mathrm{dzu}$ & & & $* !$ & & \\
\hline
\end{tabular}

The summary of the constraint ranking is shown in (10).

$$
* \# \mathrm{Z}, * \mathrm{TU}>>* \mathrm{DZ}>>\text { Ident }-\left[\mathrm{A}_{0}\right]>\text { }>\mathrm{TS}
$$

We have established the following hierarchy between the markedness constraints against affricates: $* \mathrm{DZ}>{ }^{*} \mathrm{TS}$. The ranking $* \mathrm{DZ}>>$ TS reflects the markedness of voiced affricates in the native lexicon of Japanese. The preference for voiceless affricates over voiced ones is observed in languages such as German and Russian, which possess voiceless affricates [ts] but lack the voiced counterpart. It is a plausible universal and perhaps an instance of the more general preference for voiceless obstruents over voiced ones, motivated by well-known phonetic considerations (i.e. the difficulty of maintaining vocal fold vibration in the face of oral closure). Such markedness preferences are formalised in OT by assuming that the relevant constraint rankings are fixed. See Prince and Smolensky (1993) for discussion of markedness scales in these terms.

The same $\mathrm{M} \gg \mathrm{M}$ ranking, ${ }^{*} \mathrm{DZ} \gg * \mathrm{TS}$, has a striking effect in the adaptation process. Japanese has a five vowel system, /a, i, u, e, o/. The high round back vowel $|\mathrm{u}|$ and the round schwa $\mid \boxminus$ of French are generally adapted as /u/ both in loanwords and in my adaptation data. In the category of relatively old loanwords, such as the ones shown in (11), the input sequence |tu| of the French word Toulouse is adapted with the affricate [ts]: /tsuuruuzu/, while, $|\mathrm{du}|$ of Pompidou is adapted as [do]:/poNpidoo/. The latter preserves the release feature $\left[\mathrm{A}_{\max }\right]$ of the plosive $/ \mathrm{d} /$ by lowering the vowel from $/ \mathrm{u} /$ to $/ \mathrm{o} /$.

Relatively old loans

a) /tsuuruuzu/ < tuluz $\mid$ Toulouse 'place name, loan from French' 
b) /tsuupiisu/ < tu:pi:s| two-piece(s), loan from English

c) $/$ poNpidoo/ < põpidu| Pompidou 'personal name, loan from French'

d) $/ \mathrm{kaFe}$ do Furooru $|<| \mathrm{kafe} \mathrm{dE}$ flOR $\mid$ Café de Flore 'name of a coffee shop, loan from French'

The choice of vowels in each case is explained as follows. The [high] feature of the vowel $|\mathrm{u}|$ is more important than the appearance of the voiceless affricate [ts], thus the adapted form /tsuuruuzu/ preserves the high vowel $/ \mathrm{u} /$, as shown in Tableau 6.

Tableau 6

Toulouse /tsuuruuzu/

\begin{tabular}{|l|l|l|l|l|l|}
\hline & $\ldots$ tu & $*$ TU & $*$ DZ & Ident-[high] & $*$ TS \\
\hline 1. & ..tu & $* !$ & & & \\
\hline 2. & ..to & & & $* !$ & \\
\hline $3 . \rightarrow$ & ..tsu & & & & $*$ \\
\hline
\end{tabular}

Whereas in /poNpidoo/ the more marked voiced affricate is avoided at the cost of sacrificing the vowel identity. This is easily discribed in the OT model as the insertion of the faithfulness constraint Ident-[high] within the markedness preference ranking for voiceless over voiced affricates: *DZ >> Ident-[high] >> *TS. Tableau 7 illustrates the effect of this ranking.

Tableau 7

Pompidou/poNpidoo/

\begin{tabular}{|l|l|l|l|l|l|}
\hline & $\ldots \mathrm{du}$ & $* \mathrm{TU}$ & $* \mathrm{DZ}$ & Ident-[high] & $* \mathrm{TS}$ \\
\hline 1. & $\ldots \mathrm{du}$ & $* !$ & & & \\
\hline $2 . \rightarrow$ & $\ldots \mathrm{do}$ & & & $*$ & \\
\hline 3. & $\ldots \mathrm{dzu}$ & & $* !$ & & \\
\hline
\end{tabular}

We obtain the ranking shown in (12). ${ }^{3}$

$$
* \mathrm{TU}, * \mathrm{DZ}>>\text { Ident-[high] }>>\text { *TS }
$$

The effect of the ranking, $* \mathrm{DZ}>>* \mathrm{TS}$, thus emerges here again. I consider this as an aspect of UG appearing in the adaptation process. The ranking *DZ > Ident-[high] differs from the native one, since the native sequence /du/ allows the output [dzu] without lowering the vowel height. Thus, this loanword category constitutes its own stratum (or at least it did so at the time of adaptation of these items). Of course, once the items are integrated in L1 as loanwords, speakers do 
not necessarily have access to the source words. The items may then be stored with the output sequences. Without other evidence it is impossible to decide between these alternative analyses.

In sum, we have reviewed two quite distinct places in the grammar of Japanese where the preference for voiceless affricates over voiced ones asserts itself. First, in the native vocabulary intervocalic /t/ before an $/ \mathrm{u} /$ is realised as an affricate (/natu/ $\rightarrow$ [natsu] 'summer) while /d/ is spirantised (/mikaduki/ $\rightarrow$ [mikazuki] 'increasing moon'). Second, in loanword adaptation /tu/ is realised with an affricate (Toulouse $\rightarrow$ [tsuuruuzu]) while /du/ changes the vowel (Pompidou $\rightarrow$ [poNpidoo]). While it could be argued that the former process establishes the $* \mathrm{DZ}>>$ TS ranking, it is implausible that the change of vowel that we see in Pompidou $\rightarrow$ Pompi[doo] is a direct consequence of the avoidance of [dz] seen in /mikaduki/ $\rightarrow$ [mikazuki]. After all spirantisation and lowering of a high vowel are quite different phonological substitutions. But viewed in the OT constraint-based approach, both phenomena reflect the marked status of voiced affricates relative to voiceless ones that is encoded in the fixed ranking *DZ > * TS that by hypothesis forms part of the initial stage of acquisition. If this reasoning is correct, then we see an aspect of UG emerging in the adaptation process and the latter provides a window on the former.

\section{Emergent Pattern 2: Accentuation}

I will present other cases of the emergence of UG encountered in the study of accent assignment in the adaptation process (see Shinohara 1997b, 2000 for more extensive discussion). Japanese is a pitch accent language. For many Japanese lexical items, the accent is lexical (unpredictable), while for certain others, the accent is assigned by default (predictable). Foreign word adaptation is a good vantage point to observe default accent patterns, because input words do not always contain an accent specification. According to my study of Japanese adaptation, the accentuation of adapted forms falls into two categories : 1) the accent is carried over from the accent of the source word, which is the case for the adaptations of English words ; 2) no accent is recognised in the source words and the accent is assigned by default, which is the case observed in adaptations of French words. Differing from the previous case of affricates, the accent assignment analysis does not involve lexical stratification. Since default accentuation identified in foreign word adaptations is also found in certain restricted parts of the Japanese lexicon such as proper names, certain derived words, etc. I assume that a single grammar is responsible for default accent for the entire lexicon. However the patterns appearing in French adaptation are richer than the ones found in those restricted classes. In the analysis of the default accent patterns, I have encountered several instances of the emergence of UG. Before 
we look at the data from adaptations, let us briefly explicate the pitch accent system of Tokyo Japanese.

\subsection{Pitch accent system in Tokyo Japanese}

In a Japanese word, the accent is marked by a falling pitch. The accented syllable is the one just before the drop in pitch. In the word /tama'go/ 'egg', the pitch drops after the second syllable $/ \mathrm{ma} /$, which is the accented syllable. In an accented heavy syllable, the pitch falls after the first mora. In /ko'omori/ 'bat', the first syllable is a heavy one consisting of a long vowel. In the heavy syllable, only the first mora can bear the accent. Following the traditional convention I will mark the accent with an apostrophe after the accented mora.

Let us turn to the specification of the place of accent. A Japanese word is specified as either "unaccented" or "accented". In accented nouns, the position of the accent is in most cases unpredictable. In (13), three-syllable words are followed by an accentually neutral subject marker, $\mathrm{Fga}$. Since any syllable can bear the accent, and a word can be also unaccented, there exist four possible accent patterns.

Accentuation in nouns

\begin{tabular}{|c|c|c|c|c|}
\hline followed & $\begin{array}{l}\text { me'gane-ga } \\
\text { 'glasses' }\end{array}$ & $\begin{array}{l}\text { koko'ro-ga } \\
\text { 'heart' }\end{array}$ & $\begin{array}{l}\text { otooto'-ga } \\
\text { 'brother' }\end{array}$ & \\
\hline
\end{tabular}

The accentuation of underived verbs and underived adjectives is limited to two types: accented or unaccented. In the infinitive form of the class of accented verbs, the accent falls on the syllable containing the penultimate mora (cf. (14)).

Accentuation of verbs and adjectives

\begin{tabular}{|l|ll|ll|}
\hline & accented & & unaccented & \\
\hline$\underline{\text { verbs }}$ & $\begin{array}{l}\text { tabe'ru } \\
\text { ha'iru } \\
\text { omo'o }\end{array}$ & $\begin{array}{l}\text { 'eat' } \\
\text { 'enter' }\end{array}$ & $\begin{array}{l}\text { nemuru } \\
\text { akeru }\end{array}$ & $\begin{array}{l}\text { 'sleep' } \\
\text { 'open' }\end{array}$ \\
\hline$\underline{\text { adjectives }}$ & $\begin{array}{l}\text { haja'i } \\
\text { naga'i }\end{array}$ & $\begin{array}{l}\text { 'fast' } \\
\text { 'long' }\end{array}$ & $\begin{array}{l}\text { akai } \\
\text { marui }\end{array}$ & $\begin{array}{l}\text { 'red' } \\
\text { 'round' }\end{array}$ \\
\hline
\end{tabular}

\subsection{Tracking of accent in English and French words}

In relation to accent specification, I will present now adaptations of English words (Shinohara 1997b). For the English data, three informants studying in London sent the author their adapted forms written in "kana" syllabary supplemented with pitch accent marks. ${ }^{4}$ As shown in (15), the place of accent in an adapted form of 
an English word always corresponds to the primary stress position in the English word. $^{5}$

English stress and pitch accent placement of the adapted forms of English words

\begin{tabular}{llll}
\hline Nouns & Adapted forms & Verbs & Adapted forms \\
\hline pícnic & /pi'kunikku/ & mátter & /ma'taa/ \\
ínfluence & /i'NhurueNsu/ & órganize & /o'oganaizu/ \\
beháviour & /bihe'ibijaa/ & invéstigate & /iNbe'sutigeito/ \\
techníque & /tekuni'iku/ & implý & /iNpura'i/ \\
dífficulty & /di'Fikarutii// & contríbute & /koNtori'bjuuto/ \\
\hline
\end{tabular}

The primary accent (or stress) of an English word is marked by a relative prominence manifested by an increase in amplitude and duration. The accented syllable is also the anchoring site of phrasal tones (i.e. intonation) (cf. Liberman 1975). The only acoustic correlate common between English and Japanese accents is the falling pitch, which is used as the declarative nuclear accent in English. In spite of the distinct realisations of the accent of both languages, the accented syllables in English words seem to be interpreted as carriers of a lexical accent in the Japanese adaptation process.

In contrast with the English case, in French words, no accent is recognised by Japanese speakers. Nevertheless, an accent is assigned to certain positions in the adapted forms. In French, phrase final syllables are lengthened. We might think of several reasons why French phrase final lengthening is not recognised as accent by Japanese speakers : 1) because it is fixed and predictable, it is not interpreted as lexical ; 2) the phonetic correlates (duration in the French accent vs. pitch drop in Japanese) do not allow a correspondence between them ; 3) phenomena at the phrasal level are excluded from the lexical representation. Without sufficient evidence from the adaptation of other languages, I cannot determine the reason. I will, thus, simply assume no accent specification in the French input.

\subsection{Default accentuation}

Adapted forms of French words have been accented by the informants in the following ways:

1) If the final syllable of the adapted form is light, the accent falls on the syllable containing the antepenultimate mora (see (16)).

Accent on the syllable containing the antepenultimate mora mâchicoulis |maSkuli| 'machicolation' /masi'kuri/ 


\begin{tabular}{|c|c|c|c|}
\hline$\underline{\text { travesti }}$ & |tRavEsti| & 'travesty' & /torabe'suti/ \\
\hline crudité & |kRydite| & 'raw vegetables' & /kurju'dite/ \\
\hline alerte & |alERt| & 'alert' & /are'ruto/ \\
\hline philatélie & |filateli| & 'philately' & /Fira'teri/ \\
\hline automatique & |QOmatik| & 'automatic' & /ootomati'Qku/ \\
\hline boulangerie & |bulàj Ri| & 'bakery' & /bura’Nzjuri/ \\
\hline pointe & |pwét| & 'point' & /powa'Nto/ \\
\hline
\end{tabular}

2) If the final syllable is heavy, the accent falls on the syllable containing the preantepenultimate mora (see (17))

(17)

Accent on the syllable containing the pre-antepenultimate mora
potiron
|potiRã 'pumpkin'
/po'tiroN/
$\underline{\text { sarrasin }}$
|saRazé|
'a type of wheat'
$/$ sa' razaN/
poinçon |pwésõ 'punch'
/powa'NsoN/

It follows from (16) and (17) that if we exclude the final syllable and construct a bimoraic foot from the end of these forms, the accent falls on the first mora of the foot. Hence, the basic accent position is defined as being the head of the rightmost non-final bimoraic foot :

$$
-\left(\mu^{\prime} \mu\right) \sigma \# \quad \text { (the final syllable } \sigma \text { can be light or heavy) }
$$

This bimoraic metrical structure is the one that previous research has shown to play a role in the formation of "prosodically derived" words in Japanese, including : a) hypocoristics (Tateishi 1991, Poser 1990) , b) truncation (Itô 1990, Itô \& Mester 1992, Suzuki 1995), and c) reversed language of jazz musicians (Tateishi 1991, Poser 1990, Itô, Kitagawa \& Mester 1996) :

a) Hypocoristics:

(a'ki)-tjan < aki'taka,

(ma'a)-tjan $<$ manami,

(a't)-tjan $<a^{\prime}$ tuko

b) Truncation of loanwords:

(a'ni)me < anime'esjoN 'animation',

(de'mo) < demoNsutore'esjoN 'demonstration' 
c) Japanese musicians' argot (ZG) :

(jano)pi < pijano 'piano',

(zuu)zja < zja'zu 'Jazz'

We learn from the analysis of default accentuation that the use of the bimoraic feet extends to the accent assignment in Japanese, as in many other languages. The constraints we will use for the analysis of the default accent are essentially the following (see Shinohara 1997b, 2000 for more detailed discussion) :

(20) Main constraints :

Head-left (Head-L) : Trochaic feet.

Align (F, R, PrWd, R) (AlignR) : Align right edge of every foot with the right edge of a prosodic word.

Non-Finality (NonFin) : No prosodic head (accented foot $(F)$ or syllable $(\sigma))$ of PrWd is final in PrWd.

Max/Min Foot-Binarity (Max/MinBin) : Feet are maximally/minimally binary at some level of analysis $(\mu, \sigma)$.

Parse-syllable (Parse- $\sigma$ ) : Parse every syllable into a foot.

The constraints are ranked as follows :

(21) Main ranking for the basic patterns:

NonFin $\gg$ AlignR $\gg$ Parse- $\sigma$

Max/MinBinarity, Head-Left : (One or the other is undominated in the ranking above.)

The effects of this ranking are shown in Tableau 8.

Tableau 8

mâchicoulis /masi'kuri/

\begin{tabular}{|l|l|l|l|l|l|}
\hline & maSkuli & NonFin & AlignR & Parse- $\sigma$ & Align L \\
\hline $1 . \rightarrow$ & ma(si'ku)ri & & $*$ & $* *$ & $*$ \\
\hline 2. & (ma'si)kuri & & $* * !$ & $* *$ & \\
\hline 3. & masi(ku'ri) & $\mathrm{F} !$ & & $* *$ & $* *$ \\
\hline 4. & (masi)(ku'ri) & $\mathrm{F} !$ & $* *$ & & $* *$ \\
\hline
\end{tabular}

In Tableau 8, candidate 1 is better aligned to the right than candidate 2 is. Candidate 3, though better aligned to the right than candidate 1, loses : this shows the Non-Finality constraint in force. Since Japanese words have at most one accent, I will assume there is only one foot in a Japanese prosodic word ${ }^{6}$. In order to obtain non-iterative foot-parsing, Parse-syllable is ranked under AlignR. Candidate 3 wins over candidate 4 by virtue of having a single aligned foot : the 
final feet of candidates 3 and 4 are aligned, but the first foot of candidate 4 is misaligned by two syllables.

We have seen the basic default accentuation patterns and the mechanism yielding these patterns. We will turn to the case involving accent shift effect due to the presence of epenthetic vowels in the next section.

\subsection{Vowel epenthesis and accent}

An instance of the emergence of UG appearing in the accentuation concerns the avoidance of placing accent on epenthetic vowels, a phenomenon not found in L1 Japanese grammar (due to lack of epenthesis in monomorphemic words ${ }^{7}$ ). In the adapted forms of French words, syllables containing epenthetic vowels count as prosodic constituents relevant for accent placement; however, the accent seems to shift when the predicted position is filled by an epenthetic vowel. ${ }^{8}$ In (22) and (23), adapted forms end in a light syllable, thus, we expect that the accent falls on the antepenultimate mora. As shown in (22), when an input contains a non epenthetic vowel in this position, the accent is placed on the antepenultimate mora as predicted. Epenthetic vowels are marked by italics.
a) otarie |otaRi| 'sea-lion
/o'tari/
b) mâchicoulis |maSkuli| 'machicolation'
/masi'kuri/
c) alerte $|\mathrm{alERt}|$ 'alert'
/are'rutol

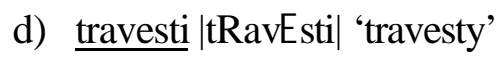
/torabe'suti/

Notice in examples c) and d) above that the epenthetic vowels after the antepenultimate mora are counted for foot construction, otherwise the accent would fall on a syllable closer to the beginning of the forms as in */a'reruto/ and */tora'besuti/.

Now we observe the case where the accent would fall on an epenthetic vowel. When the antepenultimate mora of an adapted form does not correspond to a French vowel in the input, the accent shifts, as shown in (23).
a) stylo |stilo| 'pen'
/suti'ro/
b) patronat |patRonal 'patronate' /patoro'na/
c) abricot |abRiko| 'apricot'
/aburi'ko/
d) cercle $|s E R k 1|$ 'circle'
/se'rukurul

Across languages epenthetic or "weak" vowels tend to avoid the accent. Here are a few examples from the literature : 
Epenthetic vowels: schwa in Hebrew (Prince 1975) and in Mohawk (Michelson 1988, Hagstrom 1997), /i/ in Palestinian Arabic (Brame 1973 cited in Kenstowicz 1981) ;

Weak vowels: schwa in Chukchee (Kenstowicz 1993b), high vowels in Moksan (Kenstowicz 1993b) etc.

The tendency to avoid accent on weak vowels looks clearly like the effect of a markedness constraint. But in order to distinguish an epenthetic vowel from a phonetically identical vowel that has an input correspondent, the constraint must evidently refer to the input. I will not discuss this point here and simply adopt the constraint in (24) from Alderete (1995b) that expresses this type of Input-Output faithfulness relationship.

Head(PCat)-Dep : Every segment contained in prosodic head PCat in S2 has correspondent in S1. If PCat is a prosodic head in S2, and PCat contains $\beta$ then, $\beta \in$ Range.

In our case Head(Foot)-Dep is high ranking and it will force the accent to avoid an epenthetic vowel as illustrated in Tableau 9.

Tableau 9

abricot /aburi'ko/

\begin{tabular}{|c|c|c|c|}
\hline & abRiko & Head(F)-Dep & Default Accent \\
\hline 1. $\rightarrow$ & aburi'ko & & $*$ \\
\hline 2. & abu'riko & $* !$ & \\
\hline
\end{tabular}

With Head(Foot)-Dep in the undominated position, the foot in the winning candidate must not contain an epenthetic vowel, thus, its foot parsing is /abu(ri'ko)/. Forms such as /(a')buriko/ and /abu(riko')/ are ruled out by FootBinarity and Non-Finality $(\sigma)$ respectively. See Shinohara (1997a, b, 2000) for other possible analyses.

We have seen that accented epenthetic vowels are avoided in French word adaptation. Since the Japanese lexicon lacks epenthesis, this is an effect of UG asserting itself in the context of adaptation.

\subsection{UG preference for the bimoraic foot}

Another instance of emergence of UG appears when we compare stable accent patterns with a variable pattern in the adaptation data. When the penultimate and antepenultimate syllables are light then accent systematically appears on the antepenult (as long as it is not epenthetic). But when the antepenult is heavy, then 
there is variation between penultimate and antepenultimate accent. In (25), H denotes a heavy syllable, $L$ denotes a light syllable:

Variation in HLo

1. H'LL/HL'L : a'Ntere/aNte're < intérêt 'interest'

2. H'LH/HL'H : mo'NtoroN/moNto'roN < Montholon 'place name', pa'NteoN/paNte'oN/ < Panthéon 'Pantheon'

These words contain syllable sequences which cannot be easily parsed as a bimoraic foot. In moraic languages, there are different strategies for parsing such problematic HL syllable sequences. In classical Latin, bimoraic contiguous footing is assured by syllable shortening: /HLH/ $\rightarrow$ [HLL] (Mester 1994). In Tongan, where penultimate accent is imposed, an /HL/ input appears as [LL'L]; thus a final bimoraic foot is assured by breaking up $\mathrm{H}$ into LL (Prince and Smolensky 1993). In my data, however, there is not any syllable quantity change. What we find instead is a variation in accent location'. According to the analysis in Shinohara (1997a, b, 2000), we obtain the following foot grouping in the winning candidates: ( $\left.H^{\prime}\right) L \sigma$ and $H\left(L^{\prime}\right) \sigma$ (or $\left(H^{\prime} L\right) \sigma$ and $H\left(L^{\prime}\right) \sigma$ depending on the particular analysis).

The sequence HL is difficult for a bimoraic foot parsing. If the bimoraic structure is the one preferred by UG for trochaic accent, this difficulty should be reflected in some way or other. In the default accentuation of Japanese (identified in French word adaptations), it is reflected by variability in grouping.

\subsection{Summary of the section}

The accentual data reviewed in this section have a number of implications for acquisition and UG. First, the default accent pattern is found in restricted and relatively sparsely populated sections of the Japanese lexicon: compounds and proper names. (See Shinohara (to appear) for an analysis of compound accent). Therefore a theory which would assign accent to an adapted form according to the statistically most frequent pattern in the lexicon will not work. Rather, the adaptation data (cf. English versus French adaptations) reconfirm the traditional generative assumption that inputs record unpredictable, contrastive information only. The default accent assigned by the constraint rankings in (21) steps in whenever the input lacks an accent. Given that French words are perceived as lacking an accent while English words are perceived as having an accent, only the former will be assigned an accent via the default accent schema ${ }^{10}$.

Second, the constraint barring accent on an epenthetic vowel is a truly emergent pattern because epenthesis does not operate in the native lexicon. The systematic avoidance of accent on an epenthetic vowel must arise from a 
constraint that is latent in the mature grammar and inherited from the initial state. The fact that epenthetic vowels are skipped by stress processes in a number of other languages provides support for the idea that this effect is due to a constraint belonging to UG (however it is eventually formulated).

Third, the vacillation between penultimate and antepenultimate accent for HL $\sigma \#$ sequences in the face of the stable antepenultimate accent for LL $\sigma \#$ sequences suggests that the constraints enforcing foot binarity are ranked high in the default UG constraint ranking. Both Head(F)-Dep and Foot Binarity are constraints on the internal structure of a metrical foot while Nonfinality and Alignment position the foot with respect to the edges of the word. Perhaps in the default ranking of the initial state constraints on metrical form dominate constraints on alignment. This speculation obviously awaits confirmation from first language acquisition studies.

\section{Emergent Pattern 3: Syllabification and prefinal lengthening}

This section presents two cases of emergence of UG in the analysis of "prefinal lengthening" in adaptations of French words. Stem-syllable alignment is a constraint that appears to be active only in the adaptation process. It might be thus a case of emergence of UG. The other case concerns a markedness scale for geminates. Let us first review "prefinal lengthening". When a French word ends in a single consonant, in the adapted form, the rime corresponding to this syllable is lengthened. ${ }^{11}$ It can be heavy in the following ways (lengthened rimes are underlined) :

1. It ends in the first half of a geminate consonant: /arusjubekku/ < archevêque |aRSEvEk| 'archbishop'.

2. It contains a long vowel: /madureenu/ $<$ madeleine |madlEn| 'a type of cake'.

Following Tsuchida (to appear), I interpret the prefinal lengthening as the result of alignment between the stem edge and a syllable edge. The choice between the types of lengthening is explained by a conflict among certain constraints including markedness constraints for gemination for certain types of consonants. Let us first observe some important facts.

\subsection{Facts about the prefinal lengthening}

The type of lengthening obtained depends on two factors:

a) Nature of the consonant;

b) Whether the vowel is "lengthening" or not (see below). 
Here are some examples.

a) Voiceless obstruent

When a French word ends in a voiceless obstruent, this obstruent is consistently geminated in the adapted output.

$\begin{array}{llll}\underline{\text { nappe }} & \mid \text { nap } & \text { 'table cloth' } & \text { /nappu/ } \\ \underline{\text { patte }} & \mid \text { pat } & \text { 'paw' } & \text { /patto/ } \\ \underline{\text { lac }} & \mid \text { lak } & \text { 'lake' } & \text { /lakku/ } \\ \underline{\text { mèche }} & \mid \mathrm{mES} & \text { 'lock' } & \text { /messju/ }\end{array}$

a') Voiceless obstruent preceded by a lengthening vowel

There are special cases to add to the preceding one : when the vowel in the final closed syllable is spelled with more than one letter ( $\underline{\mathrm{au}}, \underline{\mathrm{ou}}$, etc.) or with a circumflex accent $\underline{\hat{e}}$, $\underline{\hat{a}}$, etc.) the vowel can optionally lengthen instead of the consonant. I will call these vowels "lengthening vowels".

$$
\begin{array}{llcl}
\underline{\text { haute }} & \mid \text { ot } & \text { 'high' } & \text { /ooto/ or /otto/ } \\
\underline{\text { fête }} & |\mathrm{fEt}| & \text { 'party' } & \text { /Feeto/ or /Fetto/ }
\end{array}
$$

The variation in this particular case is explained as follows. The choice depends on whether the vowel is recognised by the speaker as a lengthening vowel or not. If it is, then, the vowel is lengthened; otherwise, the regular consonant gemination in a) applies.

b) Voiced fricative

In case the final consonant is a voiced fricative, it is always the vowel that is lengthened.

$$
\text { rose } \quad \text { roz } \mid \text { 'rose' /roozu/ }
$$

c) Voiced plosive or nasal stop ; variation

$$
\begin{array}{llc}
\underline{\text { robe }} & |\mathrm{RO}| \text { 'dress' } & \begin{array}{c}
\text { /robbu/ or /roobu/ } \\
\text { aide }
\end{array} \\
& |\mathrm{Ed}| \text { 'help' } & \text { /eddo/ or /eedo/ } \\
\text { pomme } & |\mathrm{pOn}| \text { 'apple' } & \text { /pommu/ or /poomu/ } \\
\underline{\text { reine }} & |\mathrm{REn}| \text { 'queen' } & \text { /rennu/ or /reenu/ }
\end{array}
$$

We now turn to analyses of these facts. 


\subsection{Alignment between stem and syllable edges}

\subsubsection{Emergence of stem-syllable alignment}

"Prefinal lengthening" is commonly observed in recent loanwords in Japanese (Hirozane 1992, Kawakami 1995 among the others). In a previous study of English loanwords, Tsuchida (to appear) analyses it in terms of alignment between morphological and prosodic categories (cf. McCarthy and Prince 1993b) with the following constraint:

(27)

Align-R (Stem, R, Syllable, R) : The right edge of the stem in the input must be aligned with the right edge of the syllable in the output. (Tsuchida to appear: $17(34))^{12}$

The lengthening of consonants observed in a) and c) in section 6.1 above is explained by this alignment: by geminating the final consonant of the input |nap| it becomes a coda, thus it satisfies constraint (27). The second half of the geminate occupies the onset of the epenthetic syllable to satisfy the Onset constraint. This analysis explains nicely why the gemination does not appear for the vowel ending words (cf. a) in (28) below) ${ }^{13}$ nor for word medial consonants (cf. b) and c) in (28)).
a) pâté |pate| 'paste'
/pate/, */patee/
b) magma |magma| 'magma'
/maguma/, */magguma/
c) pique-nique |piknik| 'picnic'
/pikunikku/, */pikkunikku/

As shown in Tableau 10, the Align-R constraint forces the insertion of a mora on the consonant. The consonant gemination is, thus, explained by this mechanism.

Tableau 10

Align R > Dep- $\mu$

\begin{tabular}{|l|l|l|l|}
\hline & lak\# & Align- $\mathrm{R}$ & Dep- $\mu$ \\
\hline $1 . \rightarrow$ & rak.ku & & $*$ \\
\hline 2. & ra.ku & $* !$ & \\
\hline
\end{tabular}

Align- $\mathrm{R}$ is a constraint observed in the adaptation process, but not in the other parts of Japanese lexicon. It is arguably another case of emergence of UG. Stemsyllable alignment is in fact found in many other languages such as: Axininca 
Campa, Bedouin Arabic, Biblical Hebrew, Kamaira (McCarthy \& Prince 1993b), Tiberian Hebrew (McCarthy 1997), and Malay (Teoh 1987).

\subsubsection{Absence of stem-syllable alignment in Sino-Japanese morphemes}

In this sub-section, we will discuss a question about learning algorithms and reranking across strata. Having said that stem-syllable alignment does not appear in the other parts of the lexicon, there is thus a discrepancy between the SinoJapanese sub-grammar and the adaptation sub-grammar ${ }^{14}$. Sino-Japanese morphemes can end in a consonant in input forms (Itô 1986), however this consonant does not geminate at the right stem edge. Here are examples of SinoJapanese (compound) words.

a) /bet/ 'separate' + /sit/ 'room' $\rightarrow$ [bes.si.tu] 'separate room'

b) /kat/ 'lively' + /doo/ 'movement' $\rightarrow$ [ka.tu.doo] 'activity'

c) $/$ bet $\rightarrow$ [bet $u]$ 'separation'

In (29) a), the first consonant of the second morpheme is geminated. This type of gemination occurs when a voiceless consonant is preceded by a morpheme final /t/ (under certain circumstances morpheme final / $\mathrm{k} /$ triggers gemination as well). The absence of this gemination in b) is explained by the anti-gemination constraint for voiced consonants (cf. the gemination scale in the following section). The point of interest in (29) is the absence of gemination of the final $/ t /$ of the second morpheme in a) and c) which violates the stem-alignment constraint. To allow the form without gemination, Dep- $\mu$ must dominate Align-R. This is illustrated by Tableau 11.

Tableau 11

Dep- $\mu$ > Align-R (Sino-Japanese)

\begin{tabular}{|l|l|l|l|}
\hline & bet\# & Dep- $\mu$ & Align- $\mathrm{R}$ \\
\hline $1 . \rightarrow$ & betu & & $*$ \\
\hline 2. & bet.tu & $* !$ & \\
\hline
\end{tabular}

The native stratum, on the other hand, does not provide any evidence for ranking these two constraints given that input noun stems do not end in a consonant. According to standard assumptions, in the initial state of UG Markedness is ranked over Faithfulness. In the Sino-Japanese grammar we observe Faithfulness (Dep- $\mu$ ) over Markedness (Align-R). Therefore, a reranking from the initial state must have taken place in the Japanese grammar through positive evidence provided by the Sino-Japanese lexicon. However, in adaptation 
of loanwords $\mathrm{M}$ ranks over $\mathrm{F}$, as in the initial state. The question thus arises as to why the adaptation grammar $(\mathrm{M} \gg \mathrm{F})$ involves a different ranking from the SinoJapanese grammar $(\mathrm{F}>>\mathrm{M})$ and furthermore one that goes in the opposite direction from the learning algorithm. Let us consider this problem together with the grammar structure of lexical strata. One possible interpretation is that $F \gg M$ is specific to the Sino-Japanese stratum while in other strata lacking positive evidence for reranking, $M \gg F$ remains. There are other features such as size restrictions that identify morphemes as belonging to the Sino-Japanese sector. Adaptations from French and English typically lack these features and hence are not assigned to the Sino-Japanese class. If we make this assumption then we can say that the $M$ > F ranking of Align- $\mathrm{R}>>$ Dep- $\mu$ inherited from the initial state remains latent in the mature grammar and emerges when given the appropriate inputs. However, under the core-periphery view of lexical strata proposed by Itô and Mester (1995a,b) the Sino-Japanese grammar stands between the native Yamato and the adaptation grammar. Furthermore, Itô and Mester (1995b) claim that strata differ simply by the relative ranking of faithfulness and markedness with more $\mathrm{F}$ > $\mathrm{Ms}$ in peripheral sectors. On this view then the passage from SinoJapanese grammar to the adaptation grammar would involve contradictory rerankings: initial/native $\mathrm{M}>\mathrm{F} \rightarrow$ Sino-Japanese $\mathrm{F}>\mathrm{M} \rightarrow$ adaptation $\mathrm{M}$ > $>$ F. We must leave this problem for a future investigation. It will be interesting to see if such stem-final gemination that we see in adaptation arises in primary language acquisition.

\subsection{Markedness ranking for gemination}

\subsubsection{Compensatory lengthening in OT}

Let us move on now to the case where a vowel lengthens. It will provide evidence for another emergent pattern. Input /roz/ 'rose' is realised as /roo.zu/ instead of /roz.zu/. From a derivational perspective we can think of this input-output mapping as follows. First, there is gemination to satisfy Align- $\mathrm{R} / \mathrm{roz} . \mathrm{zu} /$; this is followed by degemination of /zz/ but preservation of the inserted mora which is then reassigned to the preceding vowel to give /roo.zu/--a classic case of compensatory lengthening. This analysis can be translated into the OT framework by appealing to McCarthy's (1997) notion of "sympathy". The constraint *ZZ, (30) below, is one of the markedness constraints against gemination of voiced fricatives :

(30) Gemination constraint:

*ZZ: Do not geminate voiced fricatives. 
There are several constraints against different kinds of geminates which indicates that some consonants are easier to geminate than others. Given the constraint ranking established $(* Z Z)>$ Align-R $>$ Dep- $\mu)$ in Tableau 12 below, candidate 3 should be the winner.

Tableau 12

\begin{tabular}{|l|l|l|l|l|}
\hline & Roz\# & $* \mathrm{ZZ}$ & Align- $\mathrm{R}$ & Dep- $\mu$ \\
\hline 1. & roz.zu & $* !$ & & $*$ \\
\hline 2. & roo.zu & & $*$ & $* !$ \\
\hline $3 . ? \rightarrow$ & ro.zu & & $*$ & \\
\hline
\end{tabular}

We can block the incorrect/ro.zu/ and allow the correct /roo.zu/ to win by invoking a special faithfulness constraint for moraic weight to the sympathetic (indicated by $\varsigma_{9}^{3}$ in Tableau 13) but failed candidate (see (31)).

-Faith- $\mu$ : Every mora of the flowered candidate must have a correspondent in the output.

If this constraint ranks above Dep- $\mu$, it will block/ro.zu/ because the latter lacks the crucial extra mora which /roz.zu/ has.

Tableau 13

\begin{tabular}{|l|l|l|l|}
\hline & Roz\# & $\xi^{3}-$ Faith- $\mu$ & Dep- $\mu$ \\
\hline $1 . g^{3}$ & roz.zu & & $*$ \\
\hline $2 . \rightarrow$ & roo.zu & & $*$ \\
\hline 3. & ro.zu & $* !$ & \\
\hline
\end{tabular}

We obtain the following ranking:

$$
* \text { ZZ }>>\text { Align- } \mathrm{R}>>\text { Dep- } \mu
$$

毁-Faith- $\mu>$ Dep- $\mu$

We will now compare this result with the other cases of gemination in the next section.

\subsubsection{Variation}

We can now ask what are the degeminating consonants that give rise to compensatory lengthening? The voiced fricative /z/ always does (/roo.zu/ $<|\mathrm{roz}|$ rose 'rose'), while a voiceless obstruent (T) never does (/nap.pu/ < |nap| nappe 'table cloth'). For voiced stops (D) and nasals (N) there is variation between degemination and alignment: (/robbu/ or /roobu/ < robe 'dress') and (/rennu/ or 
/reenu/ < reine 'Queen'). To account for the variation, I will follow the free ranking approach taken by Reynolds (1994), Itô and Mester (1997), Anttila (1997) among others. In this approach, within a grammar constraints A and B may be unranked. That means, the constraints $\mathrm{A}$ and $\mathrm{B}$ are ranked $\mathrm{A} \gg \mathrm{B}$ in one subgrammar, and $\mathrm{B} \gg \mathrm{A}$ in the other. Each sub-grammar will allow a single candidate to win. I assume that ranking between two constraints *DD/*NN (antigemination constraints of $\mathrm{D}$ and $\mathrm{N}$ respectively) and Align- $\mathrm{R}$ is free. In Tableau 14 *DD dominates Align-R which gives /roobu/ as the optimal output; in Tableau 15 Align-R dominates *DD; this grammar allows /robbu/ to win.

Tableau 14

Sub-grammar A : *DD >> Align-R

\begin{tabular}{|c|c|c|c|c|}
\hline & Rob\# & $\xi_{9}^{3}$ Faith- $\mu$ & $* \mathrm{DD}$ & Align- $\mathrm{R}$ \\
\hline 1. $\varepsilon^{3}$ & rob.bu & & $* !$ & \\
\hline 2. $\rightarrow$ & roo.bu & & & $*$ \\
\hline 3. & ro.bu & $* !$ & & $*$ \\
\hline
\end{tabular}

Tableau 15

Sub-grammar B : Align-R >> *DD

\begin{tabular}{|l|l|l|l|l|}
\hline & Rob\# & $\varphi^{3}$ Faith- $\mu$ & Align-R & $*$ DD \\
\hline $1 . \rightarrow \xi^{3}$ & rob.bu & & & $*$ \\
\hline 2. & roo.bu & & $* !$ & \\
\hline 3. & ro.bu & $* !$ & $*$ & \\
\hline
\end{tabular}

Sub-grammar A : $* \mathrm{DD} / * \mathrm{NN}>>$ Align-R

Sub-grammar B : Align-R > *DD/*NN

Comparing the ranking in (32) with sub-grammar B in (33), the following markedness ranking for gemination obtains :

$* \mathrm{ZZ}>>* \mathrm{DD} / * \mathrm{NN}$

In sum, the crucial constraint rankings for the degemination phenomenon are reviewed in (35):

$* \mathrm{ZZ}>>\left\{{ }^{*} \mathrm{DD} / * \mathrm{NN}\right.$, Align- $\left.\mathrm{R}\right\}>$ >TT 
The relative dispreference for a voiced geminate compared to a voiceless one can be related to the well-known phonetic difficulty of maintaining voicing during an oral constriction--a plausible markedness scale inherited from the initial state grammar. The degemination of voiced fricatives is thus another emergent phenomenon. In the native vocabulary geminate /zz/ as well as geminate voiced stops and nasals are not subject to degemination. This effect only arises in the adaptation process.

\section{Summary and Implications}

In this paper, we have observed several instances of the emergence of UG in the Japanese adaptation of French words. First, in the segmental adaptation process (section 4), the UG ranking *DZ > *TS, which is already separated by Ident[Ao] in the native grammar of Japanese, is further corroborated in the adaptation data. The fact that there is affrication of $|\mathrm{tu}|$ in /tsuuruuzu/ < Toulouse but lowering of the vowel in /poNpidoo/ < Pompidou is accounted for by the insertion of Ident-[high] between *DZ and *TS. Second, the accentuation in French word adaptation data (section 5) confirms the default accentuation pattern observed in restricted areas of the Japanese lexicon. There are also two aspects of the accent patterns that may reflect UG. First, avoidance of accent on epenthetic vowels is uniquely observed in adaptation data. Second, HL $\sigma \#$ sequences are accented as either H'L $\sigma$ or HL' $\sigma$. This instability indicates the UG preference for a bimoraic foot. Finally in the syllabification data (section 6), a stem-syllable edge alignment and UG preference scale for geminate consonants emerge.

The unmarked patterns that appear in the adaptation process can be interpreted as the emergence of $\mathrm{M} \gg \mathrm{F}$ from the initial state of the grammar as defined by the leaning theory. Markedness orders are observed in two places: $* \mathrm{DZ}>>$ *TS and *ZZ > * DD/*NN > *TT. They may be phonetically-driven universal scales. One question arose when $\mathrm{M} \gg \mathrm{F}$ (stem-syllable alignment) emerged in the adaptation process in spite of the fact that the reversed order $(\mathrm{F}$ >> M) is active in the Sino-Japanese stratum. A relevant issue worthy of further study is the "core and periphery" structure of stratified lexicon (Itô and Mester 1995a, b).

Two general issues for further research arise from our consideration of these UG-emergent patterns. One issue is whether similar adaptations emerge in other languages. This is predicted to be the case if they reflect constraint rankings/parameter settings that are inherited from the initial state of UG and remain latent in the mature grammar. Another issue is the extent to which these UG reflecting patterns also emerge in second language acquisition, which is also predicted to occur on the grounds that aspects of the initial state remain in the mature L1 grammar. 


\section{References}

Alderete, J. (1995b). Faithfulness to prosodic heads, Ms. University of Massachusetts : Amherst.

Anttila, A. (1997). Deriving variation from grammar. In F. Hinskens, R. van Hout \& L. Wetzels (eds.) Variation, change and phonological theory. Amsterdam: John Benjamins.

Brame, M. (1973). On stress assignment in two Arabic dialects. In S. Anderson \& P. Kiparsky (eds.) A Festschrift for Morris Halle. New York : Holt.

Broselow, E. \& Park, H-B. (1995). Mora conservation in second language prosody. In J. Archibald (ed.) Phonological acquisition \& phonological theory, 151-168. Erlbaum.

Broselow, E., Chen, S-I. \& Wang, C. (1998). The Emergence of the unmarked in second language phonology, Studies in second language acquisition, 20, 261-280.

Davidson, L., Jusczyk, P. \& Smolensky, P. (this volume). "The initial and final state: Theoretical implications of Richness of the Base and empirical explorations".

Epstein, S. D., Flynn, S. \& Martohardjono, G. (1996). Second language acquisition: Theoretical and experimental issues in contemporary research, Behavioral and Brain Science, 19, 677-758.

Fukuzawa, H. (1997). Multiple Input-Output Faithfulness relations in Japanese. [ROA-260].

Gnanadesikan, A. (this volume). Markedness and faithfulness constraints in child phonology.

Hagstrom, P. (1997). Contextual metrical invisibility in Mohawk and Passamaquoddy. In B. Bruening, Y. Kang \& M. McGinnis (eds.) PF: Papers at the Interface, MIT Working Papaers in Linguistics 30, 113-182.

Haraguchi, S (1991). A theory of stress and accent. Foris Publication: Dordrecht.

Hayes, B. (this volume) Phonological acquisition in Optimality Theory: The early stages.

Hirozane. Y. (1992). Perception by Japanese speakers of some English sounds as the Japanese choked sound /Q/, The Bulletin of the Phonetic Society of Japan 201, 15-19. 
Inkelas, S. (1994). The consequences of optimization for underspecification, ms. University of California, Berkeley.

Itô, J. \& Mester, A. (1992). Weak layering and word binarity, LRC-92-09, Santa Cruz : University of California, Linguistic Research Center.

Itô, J. \& Mester, A. (1995a). Japanese phonology. In J. Goldsmith (ed.) The Handbook of Phonological Theory, 817-838, Oxford: Blackwell.

Itô, J. \& Mester, A. (1995b). The core-periphery structure of the lexicon and constraints on reranking. In J. Beckman, L. Dickey \& S. Urbanczyk (eds.) UMOP Papers in optimality theory 18., 181-209, Cambridge MA: UMass Amherst.

Itô, J. \& Mester, A. (1997). Correspondence and compositionality: The ga-gyo variation in Japanese phonology. In I. Roca (ed.) Derivations and constraints in phonology. Oxford: Clarendon Press.[ROA-146]

Itô, J. (1986). Syllable theory in prosodic phonology, Ph.D. Dissertation, Cambridge MA : Uiversity of Massachusetts, Amherst.

Itô, J. (1990). Prosodic minimality in Japanese. InK. Deaton et al. (eds.) CLS 26, Part II: Papers from the parasession on the syllable in phonetics and phonology, 213-39. Chicago : CLS, University of Chicago.

Itô, J., Kitagawa, Y. \& Mester, A. (1995). Prosodic faithfulness and correspondence: Evidence from a Japanese argot, Journal of East Asian Linguistics 5, 217-294.

Katayama, M. (1995). Loanword accent and minimal reranking in Japanese, Phonology at Santa Cruz 4, 1-12.

Katayama, M. (1997). Optimality theory and Japanese loanword phonology, $\mathrm{PhD}$. Dissertation, University of California at Santa Cruz.

Kawakami, I. (1995). Shakuyougo ni miru sokuonka to rizumushoutotsu (Consonant gemination in loanword phonology and rhythm clash), Gengokenkyuu 108, 46-73.

Kenstowicz, M. (1981). Vowel harmony in Palestinian Arabic: a suprasegmental analysis, Linguistics 19, 449-465.

Kenstowicz, M. (1993b). Peak prominence stress systems and optimality theory, Proceedings of the 1st International Conference on Linguistics at Chosun University, 7-22. Kwangiu, Korea: Foreign Culture Research Institute Chosun University. 
Liberman, M (1975). The intonational system of English, Ph.D. Dissertation, Cambridge MA:MIT.

McCarthy, J \& Prince, A. (1993b). Generalized alignment, Yearbook of Morphology, 79-153.

McCarthy, J. \& Prince, A (1995). Faithfulness and reduplicative identity. In J. Beckman, L. Dickey \& S. Urbanczyk (eds.) UMOP Papers in Optimality Theory 18, 249-384. Cambridge MA: University of Massachusetts, Amherst.

McCarthy, J. (1997). Sympathy \& phonological opacity, Handout Hopkins Optimality Theory Workshop/Maryland Mayfest.

McCawley, J.D. (1968). The phonological component of a grammar of Japanese. The Hague: Mouton.

Mester, A. (1994). The quantative trochee in Latin, NLLT 12, 1-62.

Michelson, K (1988). A comparative study of Lake-Iroquoian accent, Dordrecht : Kluwer.

Paradis, C. \& LaCharité, D. (1997). Preservation and minimality in loanword adaptation, Journal of Linguistics 33.1, 379-430.

Paradis, C. \& Lebel, C. (1994). Constraints from segmental parameter settings in loanwords: core and periphery in Quebec French, Toronto Working Papers in Linguistics 13. 1, 75-94.

Poser, W. (1990) : Evidence for foot structure in Japanese, Language 66, 78105.

Prince, A. \& Smonlensky, P. (1993). Optimality theory: Constraint interaction in generative grammar, ms. Rutgers University.

Prince, A. \& Tesar, B. (this volume). Learning phonotactic distributions.

Prince, A. (1975). The phonology and morphology of Tiberian Hebrew, Ph.D. Dissertation. Cambridge MA: MIT.

Reynolds, B. (1994). Variation and Phonological Theory. Ph.D. dissertation. Philadelphia, PA: University of Pennsylvania.

Shinohara, S. (1996): The roles of the syllable and the mora in Japanese adaptations of French words, Cahiers de Linguistique - Asie Orientale 25(1), 87-112.

Shinohara, S. (1997a). Default accentuation and foot structure in Japanese: analysis of Japanese adaptation of French words. In B. Bruening, Y. Kang 
\& M. McGinnis (eds.) PF: Papers at the Interface MIT Working Papers in Linguistics 30, 263-290.

Shinohara, S. (1997b). Analyse phonologique de l'adaptation japonaise de mots étrangers. Thèse de doctorat, Université Paris III. [ROA-243].

Shinohara, S. (2000). Default accentuation and foot structure in Japanese : Evidence from Japanese adaptations of French words, Journal of East Asian Linguistics vol 9,1, 55-96.

Shinohara, S (to appear). Metrical constraint and word identity in Japanese compound words. In J. Rifkin \& M-H. Côté (eds.) MITWorking Papers in Linguistics.

Silverman, D. (1992). Multiple scansions in loanword phonology: Evidence from Cantonese, Phonology 9, 289-328.

Steriade, D. (1993). Closure, release and nasal contours. In M. Hoffman and R. Krakow (eds.) Nasals, nasalization and the velum, 401-470. San Diego: Academic Press.

Suzuki, H. (1995). Minimal words in Japanese, Proceedings of CLS 31.

Tateishi, K. (1991). Les implications théoriques du langage des musiciens japonais, Langages 101, 51-72.

Teoh, B.S. (1987). Geminates and inalterability in Malay, Studies in the Linguistics Science 17.2, 125-136.

Tsuchida, A (to appear). English loans in Japanese: Constraints in loanword phonology, ms. Ithaca: Cornell University.

Walter, H. (1988) : Le français dans tous les sens, Paris; Robert Lafont. 
*I wish to thank René Kager, Wim Zonneveld and the audience at the Utrecht Workshop June 1998 and participants in the Phonology Circle in November 1998 at MIT for useful comments. Special thanks are due to Michael Kenstowicz for helpful discussions on the topics discussed in this paper during my visit to MIT. I thank Ruben van de Vijver and Joe Pater for carefully reading the manuscript and making valuable comments and suggestions. But I am solely responsible for any errors. My son was born during the revision of this paper, which encouraged me to continue studies of phonological acquisition.

${ }^{1}$ Hereafter, the input phonemic sequences are presented in vertical lines || ; the adapted forms in Japanese phonemic sequences are indicated by / /; [ ] indicates any phonetic output. Pitch accents are marked by an apostrophe after the accented mora.

${ }^{2}$ Note that the Japanese / $\mathrm{u} /$ phoneme is realised as a relatively centralised high vowel. One may suspect that assibilation represents a process of assimilation between $[\mathrm{t} / \mathrm{d}]$ and high/frontness of the following vowel. But I must leave the nature of this phenomenon for a topic of future investigation.

3 Assibilation is violated in relatively new loanwords as well as in my data from adaptation : input sequences $|\mathrm{t} / \mathrm{d}|$ followed by a high vowel are adapted without assibilation : /tudei/ < Today (part of the title of a column in a news paper), /dubai/ < Dubai (loanword); /tuzjuuru/ $<|\mathrm{tuJ} \mathrm{uR}|$ toujours 'always', /duuzu/ < duz| douze 'twelve' (French word adaptations). Here Ident- $\left[\mathrm{A}_{0}\right]$ is promoted in front of $* \mathrm{TU}$.

When the vowel is epenthetic, in both the relatively old and the recent loan classes the vowel is lowered to $/ \mathrm{o} /$ from the regular epenthetic vowel $/ \mathrm{u} /$ found in the other environments (in adaptation, it fluctuates between $/ \mathrm{o} / \mathrm{and} / \mathrm{u} /$ ), but this time lowering occurs after both /t/ and /d/ : (in the examples below, epenthetic vowels are marked by italics.)

a) $/$ katoriin $u$ donuub $u /<|\mathrm{katRin} \mathrm{dEnOv}|$ Catherine Deneuve 'personal name', loanword from French

b) $/$ batt $o /<\mid$ bat $\mid$ bat, loanword from English

c) $/$ es $u$ toradd $o /<\mid$ EstRad $\mid \underline{\text { estrade, }}$,'stage', adaptation (with variation /es $u$ turadd $u /$ )

In epenthetic vowels, vowel features are absent in the input ; consequently Ident-[high] does not determine the winner. Between candidates 2 and 3 in the tableau below, candidate 2 respecting $*$ TS is the winner, unlike the case of $/$ tsuuruuzu/ $<$ Toulouse with a lexical $/ \mathrm{u} /$ that violates *TS and respects higher ranked Ident-[high].

bat /batto/

\begin{tabular}{|l|l|l|l|l|l|}
\hline & bat & Assib & $* \mathrm{DZ}$ & Ident-[high] & $* \mathrm{TS}$ \\
\hline 1. & battu & $* !$ & & & \\
\hline $2 . \rightarrow$ & batto & & & & \\
\hline 3. & battsu & & & & $* !$ \\
\hline
\end{tabular}

${ }^{4}$ The Japanese writing system itself does not indicate the pitch accent. My informants for the English data were able to identify accent locations and knew also the notation.

5 Established loanwords from English do not always carry accent on the syllable corresponding to the original accent position. Such words are often accented according to the default accentuation that we will discuss shortly : /hariu'ddo/ < Hóllywood (McCawley 1968, Haraguchi 1991, Suzuki 1995, Katayama 1995, 1997). Some others are unaccented: $/$ kariforunia/ < Califórnia. Non uniformity of accent patterns in loanwords may be due to dialectal variability of adapters and to the fact that they can be accented on the basis of written forms by a speaker who has no access to the source language. 
${ }^{6}$ Some of the four-mora forms of prosodically derived words, namely the abbreviated compounds and words in the reverse language, can be analysed as comprising two feet : (waa)(puro) 'word processor', (hi:)(ko:) 'coffee'. And these four-mora forms are systematically unaccented. I therefore suspect a relationship between the two-foot structure and its unaccentedness. The presence of only one foot might be a condition for the accent. But I leave this as a topic for future investigation.

${ }^{7}$ In compound words the accent can be aligned with a morpheme boundary : kami'kaze < ka'mi 'divine' +kaze 'wind'. Consequently in Sino-Japanese compounds where a morpheme can end in a consonant (Itô 1986) an epenthetic vowel can receive the boundary accent : gaku'moN < gak + moN 'study'. I think in this case, the alignment constraint overrides the constraint barring the accent on an epenthetic vowel that I will discuss shortly. This is consistent with multi-morphemic adapted forms : /suburen $u$ 'te/ < souveraine-té |suvREnte| 'sovereignty'.

${ }^{8}$ There are loanwords accented on an epenthetic vowel: kuris $u$ 'mas $u<$ Christmas. When loanwords are written in Japanese, there is no indication of epenthetic status of vowels. Loanwords can be accented on the basis of the written form by a speaker who has no access to the source sounds.

${ }^{9}$ In Japanese native proper names where the default accentuation is detectable, a HLH sequences mostly receives initial accent (e.g. /ka'Nziroo/, /ka'NemoN/), whereas HLL seems to be uniformly unaccented. However, the data are too skanty to conclude that L1 default patterns on the HLH shape are distinct from the result in the adaptation data.

${ }^{10}$ This implies that the unaccented class in Japanese must be considered "marked": given a choice, it is more optimal for a word to have an accent than to lack one.

${ }^{11}$ A somewhat parallel case is observed for word final obstruent-liquid clusters, while other word-final clusters do not trigger any lengthening. We won't discuss cases with word-final clusters in this paper, see Tsuchida (to appear) among the others for similar phenomena in loanwords from English and Shinohara (1996, 1997b) for French adaptations.

${ }^{12}$ As is stated, this constraint forces an alignment between a stem in the input and a syllable edge in the output, which is at odds with the standard OT assumption where the output does not refer to the input properties. However, we won't be concerned with this problem here and we will use Align-R to mean the alignment between the stem and the syllable on the output level.

${ }^{13}$ Exception: when the vowel is a "lengthening" one mentionned in 6.1, a vowel can optionally be long in any position.

${ }^{14}$ Sino-Japanese morphemes constitute their own stratum: compared to the native lexicon, Sino-Japanese morphemes allow freer distribution of segments but their size is limited to two moras. 